\title{
Relationship between depression and exacerbations in COPD
}

\author{
J.K. Quint, R. Baghai-Ravary, G.C. Donaldson and J.A. Wedzicha
}

\begin{abstract}
Chronic obstructive pulmonary disease is associated with exacerbations. Some patients are prone to frequent exacerbations and these individuals have a worse quality of life, greater limitation of their daily activity and faster disease progression than patients with less frequent exacerbations.
\end{abstract}

A prospective study in a well-characterised cohort was performed and it was assessed whether depression, as determined by the Centre for Epidemiologic Studies Depression Scale, was related to exacerbation frequency, systemic inflammation and various social factors. The associations of any increase in depressive symptoms at exacerbation were also investigated.

Frequent exacerbators had a significantly higher median (interquartile range) baseline depression score than infrequent exacerbators (17.0 (7.0-25.0) and 12.0 (6.0-18.0), respectively). Depressed patients spend significantly less time outdoors and had significantly worse quality of life as measured by the St George's Respiratory Questionnaire. Depression increased significantly in patients from baseline to exacerbation (12.5 (5.0-19.0) and 19.5 (12.0-28.0) respectively).

The present study is the first to show a relationship between depression and exacerbation frequency in patients with chronic obstructive pulmonary disease. The finding that frequent exacerbators are more depressed than infrequent exacerbators is relevant, as exacerbation frequency is an important outcome measure in chronic obstructive pulmonary disease.

KEYWORDS: Chronic obstructive pulmonary disease, depression, exacerbation frequency, exacerbations, St George's Respiratory Questionnaire

hronic obstructive pulmonary disease (COPD) is characterised by chronic airflow limitation that is not fully reversible, progressive and is associated with a range of pathological changes in the lung, significant comorbidities and extra-pulmonary manifestations, including physical factors and psychological factors such as anxiety and depression [1]. The disease is interspersed with exacerbations; periods of acute symptomatic, physiologic and functional deterioration. During exacerbation, pulmonary symptoms worsen, 6-min walking distance decreases [2], peripheral muscle weakness worsens [3] and there is a fall in outdoor activity for up to 5 weeks after the onset of the exacerbation [4].

Exacerbations have important consequences for patients and healthcare providers, such as a negative impact on health-related quality of life $[5,6]$, pulmonary function [7], utilisation of healthcare resources [8] and survival [9]. Some patients are prone to frequent exacerbations and these individuals have a worse quality of life [5], greater limitation of their daily activity [4], spend less time outdoors and have faster disease progression [10, 7] than patients with less frequent exacerbations.

Depression is a recognised complication of many chronic diseases, including COPD [11-13]. Some studies have suggested depression is more common in COPD, with the prevalence increasing with increasing severity of disease, from $19.6 \%$ in mild-to-moderate disease to $25 \%$ in severe disease [11]. Other studies have found a much lower prevalence of depression, similar to that of the general population [14]. Recognition of depression is important as it affects quality of life and identification and intervention in these cases with antidepressants may improve functional capacity and quality of life [15]. However, there is a need for better understanding of the factors associated with depression.

A prospective study was performed in a wellcharacterised cohort and for the first time, it was assessed whether depression was related to exacerbation frequency. The relationships between depression and systemic inflammation,
AFFILIATIONS

Academic Unit of Respiratory

Medicine, University College London, London, UK

CORRESPONDENCE

J.A. Wedzicha

Academic Unit of Respiratory

Medicine

University College London

Hampstead Campus

Rowland Hill Street

London NW3 2PF

UK

Fax: 442074726141

E-mail: j.a.wedzicha@

medsch.ucl.ac.uk

Received:

September 112007

Accepted after revision:

February 042008

\section{SUPPORT STATEMENT}

Funding was provided for this study by a grant from the National Institute of Health, USA; R01 HL082578-01.

STATEMENT OF INTEREST

None declared. 
various social factors and the associations of any increases in depressive symptoms at exacerbation were also assessed in order to see whether predictions could be made about which patients would become more depressed at the time of an exacerbation.

\section{METHODS}

\section{Patient recruitment}

A total of 169 patients from the London COPD study were included over a 1-yr period (May, 2006 to May, 2007). The recruitment and monitoring of patients in the London COPD study has previously been described [16]. The present data have not been previously reported. All patients had COPD as defined by a post-bronchodilator forced expiratory volume in one second (FEV1) to forced vital capacity (FVC) ratio of $<70 \%$ and a $\beta_{2}$-agonist reversibility of $<15 \%$ or $200 \mathrm{~mL}$. Patients were excluded if they had other significant respiratory or inflammatory diseases.

Patients were recruited when stable with no exacerbations in the preceding month. At recruitment, daily respiratory symptoms, smoking history, exacerbation history and drug history were recorded. Information was collected regarding social contacts. Height and weight were measured along with baseline lung function using a volumetric storage spirometer (Vitalograph 2160; Maids Moreton, Buckingham, UK). Blood was collected to test for C-reactive protein (CRP) and interleukin (IL)-6. This study was approved by the Royal Free Hospital Research Ethics Committee (London, UK) and patients gave written informed consent.

Patients completed a St George's Respiratory Questionnaire (SGRQ), a Medical Research Council (MRC) dyspnoea score [17] and a Center for Epidemiologic Studies Depression Scale (CES-D). The SGRQ is designed to measure health impairment in patients with COPD [18]. There are several questionnaires validated to assess depressive symptoms, most of which include symptoms of anxiety. These include: the Hospital Anxiety and Depression Scale; the Symptom Distress Scale; the Minnesota Multiphasic Personality Inventory; and the Beck Depressive Inventory. Anxiety has been shown to be linked to COPD and as the present study concentrated on depression, the CES-D was chosen. The CES-D is a 20-question questionnaire which assesses the frequency and duration of symptoms associated with depression [19]. This score has been validated to measure change and improvements in depressive symptoms. A score of $\geqslant 16$ classifies a person as having depressive symptoms, validated with Diagnostic and Statistical Manual of Mental Disorders (DSM ${ }_{\circledR}$ )-IV criteria for clinical depression [20]. This questionnaire has been used to investigate depressive symptoms in chronic diseases, including COPD [11]. The maximum score attainable is 60 .

\section{Exacerbations}

Patients completed daily diary cards, recording any increase in daily respiratory symptoms and hours spent outside the home. They contacted the study team if they experienced an increase in their daily respiratory symptoms and were usually reviewed within $24 \mathrm{~h}$.

Exacerbations were defined according to the following definition: two symptoms (one of which must be major) on 2 consecutive days or whether the patient was considered to have suffered an exacerbation according to the opinion of the attending clinician [21]. Major symptoms were increased dyspnoea, sputum volume or sputum purulence; minor symptoms were increased cough, wheeze, sore throat or coroyzal symptoms. This definition reflects changes in quality of life [5], inflammation [22] and FEV1 decline [7].

At an exacerbation visit, information was collected on symptom type, duration of symptoms and social contacts. Spirometry was performed and blood taken for IL-6 and CRP testing. Patients also completed a CES-D questionnaire. All exacerbations were treated with bronchodilators, antibiotics and/or oral steroids as judged by the clinician. Questionnaires were administered or blood samples taken prior to the initiation of treatment.

\section{Exacerbation frequency}

Exacerbation frequency was based on the median exacerbation frequency in the cohort [21]. Patients were defined as "frequent exacerbators" if they had three or more exacerbations in the preceding year and as "infrequent exacerbators" if they had less than three exacerbations in the previous year. The number of exacerbations was obtained by counting the number of exacerbations in the preceding year recorded on the diary card.

\section{Time outdoors}

The time outdoors for baseline and exacerbation visits was calculated as the average time spent outdoors from 3 days before the day the patient attended the clinic, to 3 days after. A 7-day period was chosen to eliminate any variation due to specific days of the week.

\section{Patient blood sampling and measurement of inflammatory markers}

A total of $7 \mathrm{~mL}$ of venous blood was collected and centrifuged at $224 \times g$ for $10 \mathrm{~min}$ at $4^{\circ} \mathrm{C}$ within $2 \mathrm{~h}$ of collection. The serum was then separated and stored at $-80^{\circ} \mathrm{C}$ until later analysis.

Serum IL-6 was quantified using commercial sandwich ELISA kits (R\&D Systems, Abingdon, UK). Serum CRP was measured in the present authors' hospital laboratory using an Olympus luminometric analyser (Cobas, Roche, Burgess Hill, UK). The limits of detection for serum IL-6 and CRP were $0.7 \mathrm{pg} \cdot \mathrm{mL}^{-1}$ and $0.3 \mathrm{mg} \cdot \mathrm{L}^{-1}$, respectively.

\section{Statistical analysis}

The Kolmogorov-Smirnov test of normality was applied to data. Normally distributed data were expressed as mean $\pm \mathrm{SD}$ and skewed data as median (interquartile range (IQR)). Skewed data were log transformed in order to obtain a normal distribution. Comparisons between baseline and exacerbation and between frequent and infrequent exacerbators were made using paired and unpaired t-tests as appropriate. Pearson correlation was used to assess parametric data and Spearman rank was used to assess nonparametric correlations. The Chisquared test was used to assess the relationship between exacerbation frequency and depression. A one-way ANOVA was used to look at the relationship between MRC score and hours outdoors. Linear regression analysis was used to look at 
confounding factors affecting depression scores. For all statistical tests, a p-value of $\leqslant 0.05$ was considered significant.

In order to identify the features of depression that changed at exacerbation, baseline depression scores and principal component analysis (varimax rotation with Kaiser normalisation) were used to identify five summary groupings that explained the pattern of correlations within the 20-question dataset. The five factors explained $61 \%$ of the variance. Questions with a rotated component of $>0.5$ were considered sufficiently similar to be grouped together. Changes in patient scores between baseline and exacerbation, in these five groups, were averaged and compared using a paired t-test. The groups were termed: "depressive feelings" (questions 3, 6, 10, 17 and 18); "activity" (questions 2, 7, 11 and 20); "feelings of self-hatred" (questions 15 and 19); "reflective feelings" (questions 1 and 13); and "feelings of positivity" (questions 4, 8, 12 and 16).

\section{RESULTS}

\section{Baseline patient characteristics}

Of the 169 patients studied, 95 were male and 74 were female. The baseline characteristics of the cohort are reported in table 1 with further subdivision according to exacerbation frequency in table 2. Patients had a mean FEV1 of $1.13 \mathrm{~L}$ (47\% predicted). The mean \pm SD CES-D score for all patients was $14.9 \pm 11.1$. A total of $15(8.9 \%)$ patients had a clinical diagnosis of depression, 13 of whom were on antidepressants and two patients were not on antidepressants, and had CES-D scores of $18.2 \pm 12.4$ and $34.0 \pm 12.7$, respectively.

\section{Exacerbation frequency and depression}

A total of 61 patients were classified as frequent exacerbators and 106 as infrequent exacerbators. Two patients did not have their exacerbation frequency calculated due to insufficient

\begin{tabular}{|c|c|c|}
\hline \multirow[t]{2}{*}{ TABLE 1} & \multicolumn{2}{|c|}{$\begin{array}{l}\text { Baseline characteristics, St George's Respiratory } \\
\text { Questionnaire (SGRQ) scores and depression } \\
\text { scores of the } 169 \text { patients studied }\end{array}$} \\
\hline & & Total cohor \\
\hline \multicolumn{2}{|l|}{ Age yrs } & $70.9 \pm 8.6$ \\
\hline \multicolumn{2}{|c|}{ Time outdoors $\mathrm{h}$} & $3.4 \pm 2.3$ \\
\hline \multicolumn{3}{|c|}{$\mathrm{FEV}_{1}$} \\
\hline \multicolumn{2}{|l|}{ L } & $1.1 \pm 0.5$ \\
\hline \multicolumn{2}{|l|}{$\%$ pred } & $47.0 \pm 18.9$ \\
\hline \multicolumn{2}{|l|}{ FVC L } & $2.4 \pm 0.9$ \\
\hline \multicolumn{2}{|l|}{ BMI $\mathrm{kg} \cdot \mathrm{m}^{-2}$} & $26.3 \pm 5.5$ \\
\hline \multicolumn{2}{|c|}{ Smoking history pack-yrs } & $48.5 \pm 33.7$ \\
\hline \multicolumn{3}{|c|}{ SGRQ } \\
\hline \multicolumn{2}{|l|}{ Total } & $51.0 \pm 17.6$ \\
\hline \multicolumn{2}{|l|}{ Activity } & $67.1 \pm 22.1$ \\
\hline \multicolumn{2}{|l|}{ Impact } & $38.1 \pm 18.7$ \\
\hline \multicolumn{2}{|c|}{ Symptoms } & $62.1 \pm 20.1$ \\
\hline \multicolumn{2}{|c|}{ MRC dyspnoea score } & $2.9 \pm 1.2$ \\
\hline \multicolumn{2}{|c|}{ Depression score } & $14.9 \pm 11.1$ \\
\hline
\end{tabular}

Data are presented as mean \pm SD. FEV1: forced expiratory volume in one second; $\%$ pred: \% predicted; FVC: forced vital capacity; BMI: body mass index; MRC: Medical Research Council. diary card data. Frequent exacerbators had a significantly higher median (IQR) baseline depression score than infrequent exacerbators (17.0 (7.0-25.0) and 12.0 (6.0-18.0), respectively; $\mathrm{p}=0.03$; fig. 1). When the present data were analysed using a cut-off of clinical depression score of 16, exacerbation frequency was still found to be related to CES-D score $(p=0.01)$. Of the infrequent exacerbators, 35\% scored $>16$ at baseline compared with $54 \%$ of the frequent exacerbators.

Multiple linear regression analysis confirmed that differences observed in CES-D scores between frequent and infrequent exacerbators were not due to confounding factors, such as smoking $(\mathrm{p}=0.03)$.

\section{Systemic inflammation and depression}

Of the total cohort, in the stable state, 142 patients had CRP measured and 155 had plasma IL-6 measured. There was no relationship between baseline CRP or baseline serum IL-6 and depression score; $r=-0.02$ and $\mathrm{p}=0.77$ and $\mathrm{r}=-0.09$ and $\mathrm{p}=0.25$, respectively. However, baseline CRP and serum IL-6 were significantly related $(\mathrm{r}=0.20, \mathrm{p}=0.02)$.

\section{SGRQ and social variables}

A total of 160 patients completed the SGRQ when stable. There was a significant relationship between worse (higher) total SGRQ scores and greater CES-D scores $(\mathrm{r}=0.47, \mathrm{p}<0.001)$. The three domains of the SGRQ were also strongly related to CES-D score (activity: $\mathrm{r}=0.32, \mathrm{p}<0.001$; impact: $\mathrm{r}=0.49$, $\mathrm{p}<0.001$; and symptoms: $\mathrm{r}=0.35, \mathrm{p}<0.001$; fig. 2 ). CES-D scores were also associated strongly with the MRC dyspnoea scores $(\mathrm{r}=0.31, \mathrm{p}<0.001)$. CES-D scores increased by 1.2 points with a 4-unit measure in total SGRQ. Multiple linear regression allowing for exacerbation frequency found that SGRQ score was independently significantly associated with depression $(\mathrm{p}<0.001)$, with a 2.4-unit change in CES-D score corresponding to a 4-unit change in SGRQ score $\left(\mathrm{r}^{2}=0.3\right)$.

Data on time spent outdoors were collected for 96 patients at baseline and 45 at an exacerbation visit. Patients who spent less time outdoors were more depressed $(r=-0.34, p=0.001$ (fig. 3)) and this was related to a worse quality of life as measured by the SGRQ $(\mathrm{r}=-0.22, \mathrm{p}=0.03)$.

Females were more depressed than males with a mean \pm SD CES-D score of $18.3 \pm 12.6$ compared with $12.2 \pm 9.0$ for males $(p=0.001)$. Depression scores were higher in those who lived alone compared to those cohabiting $(18.9 \pm 12.6$ and $11.6 \pm 8.6$, respectively; $p<0.001)$. CES-D also related to the number of people indoors; individuals were less depressed the more people they lived with $(r=-0.21, p=0.007)$ and, specifically, were less depressed if they lived with a spouse $(p<0.001)$. Sex, exacerbation frequency, living alone and MRC dyspnoea score were all independently related to CES-D score $(p<0.001$, $\mathrm{p}=0.009, \mathrm{p}=0.001$ and $\mathrm{p}=0.005$, respectively).

Depression scores were similar in current $(n=53)$ and exsmokers $(n=116 ; p=0.3)$ and CES-D score was not related to smoking history $(\mathrm{r}=0.58, \mathrm{p}=0.46)$.

\section{Exacerbation characteristics}

A total of 70 patients, 39 frequent and 31 infrequent exacerbators, completed the CES-D at an exacerbation visit. The baseline characteristics of these patients are shown in 


\begin{tabular}{|c|c|c|c|}
\hline & Frequent exacerbators & Infrequent exacerbators & p-value \\
\hline Age yrs & $70.7 \pm 8.5$ & $71.1 \pm 8.5$ & 0.77 \\
\hline Time outdoors $h$ & $3.4 \pm 1.9$ & $3.5 \pm 2.5$ & 0.90 \\
\hline$\%$ pred & $41.7 \pm 15.3$ & $49.7 \pm 20.0$ & 0.005 \\
\hline FVC L & $2.2 \pm 0.8$ & $2.53 \pm 0.9$ & 0.03 \\
\hline $\mathrm{BMI} \mathbf{~ k g} \cdot \mathrm{m}^{-2}$ & $25.9 \pm 4.7$ & $26.5 \pm 6.0$ & 0.50 \\
\hline Smoking history pack-yrs & $49.2 \pm 28.3$ & $48.4 \pm 36.1$ & 0.89 \\
\hline \multicolumn{4}{|l|}{ SGRQ } \\
\hline Total & $59.8 \pm 14.5$ & $46.0 \pm 17.2$ & $<0.001$ \\
\hline Depression score & $17.7 \pm 12.4$ & $13.6 \pm 10.0$ & 0.03 \\
\hline
\end{tabular}

Data are presented as mean \pm SD. FEV1: forced expiratory volume in one second; \% pred: \% predicted; FVC: forced vital capacity; BMI: body mass index; SGRQ: St George Respiratory Questionnaire; MRC: Medical Research Council.

table 3. The CES-D increased significantly from baseline to exacerbation (mean \pm SD CES-D scores of $14.6 \pm 11.8$ and $20.3 \pm 10.4$, respectively; $\mathrm{p}<0.001$; fig. 4 ; median (IQR) 12.5 (5.0-19.0) and 19.5 (12.0-28.0), respectively; $p=0.003)$. In the frequent exacerbators, the baseline CES-D score increased on average by $5.0 \pm 9.4$ points at exacerbation, and in the infrequent exacerbators the CES-D increased on average by $6.7 \pm 9.4$ at exacerbation $(p=0.43)$. Of the cohort, $42 \%$ scored above 16 on the CES-D at baseline and $60 \%$ at exacerbation.

\section{Exacerbation inflammatory markers and depression}

CRP and IL-6 were measured in 35 patients at an exacerbation visit. CRP and IL-6 increased from baseline to exacerbation

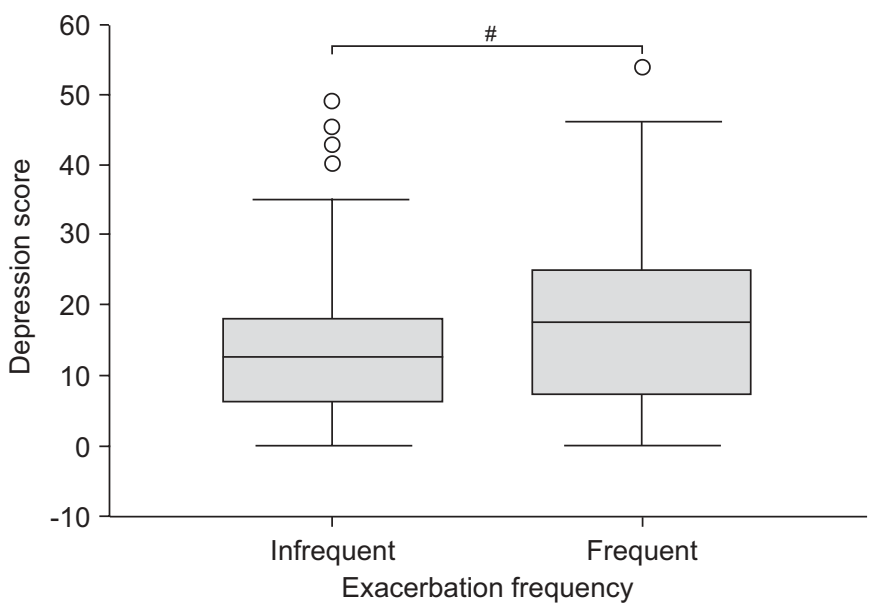

FIGURE 1. Baseline depression scores in infrequent $(n=106)$ and frequent $(n=61)$ exacerbators. Data are presented as median, with the boxes representing the interquartile range and the whiskers representing SD. $\bigcirc$ : extreme outliers. \# : $p=0.03$ (Mann-Whitney) $(p=0.001$ and $p=0.07$, respectively). The increase in CRP correlated with the increase in IL-6 $(r=0.62, p<0.001)$ but not the change in CES-D $(r=0.12$ and $p=0.48$, and $r=0.25$ and $\mathrm{p}=0.11$, respectively). Exacerbation CRP and IL-6 levels were not related to the CES-D exacerbation score $(\mathrm{r}=-0.01$ and $\mathrm{p}=0.95$, and $\mathrm{r}=-0.08$ and $\mathrm{p}=0.66$, respectively).

The mean $\pm \mathrm{SD}$ duration of exacerbation symptoms was $13.2 \pm 9.6$ days. There was no relationship between the change in depression score from baseline to exacerbation and the length of the exacerbation, the time taken to present for treatment of the exacerbation, symptom count or individual symptoms at exacerbation. There was also no relationship between exacerbation depression score and time to the next exacerbation. Only two patients were hospitalised at exacerbation in the cohort and so the effect of hospitalisation and depression was unable to be studied.

No baseline factors (e.g. FEV1, FVC, age or inflammatory markers) predicted the change in CES-D score from baseline to exacerbation. There were no specific symptoms at exacerbation or pattern of symptoms at presentation of exacerbation associated with greater risk of depressive symptoms.

\section{Principal component analysis groupings}

Scores in all five subgroups of the PCA changed significantly from baseline to exacerbation, except for feelings of self-hatred (difference of $0.05 ; \mathrm{p}=0.46$ ). Feelings of positivity and activity increased at exacerbation (difference of $-0.30 ; p=0.02$ and difference of $-0.41 ; p=0.001$, respectively). Reflective feelings and depressive feelings increased (difference of $-0.48 ; p \leqslant 0.001$ and difference of $-0.25 ; p=0.06$, respectively). The largest change between baseline and exacerbation was seen in reflective feelings. 

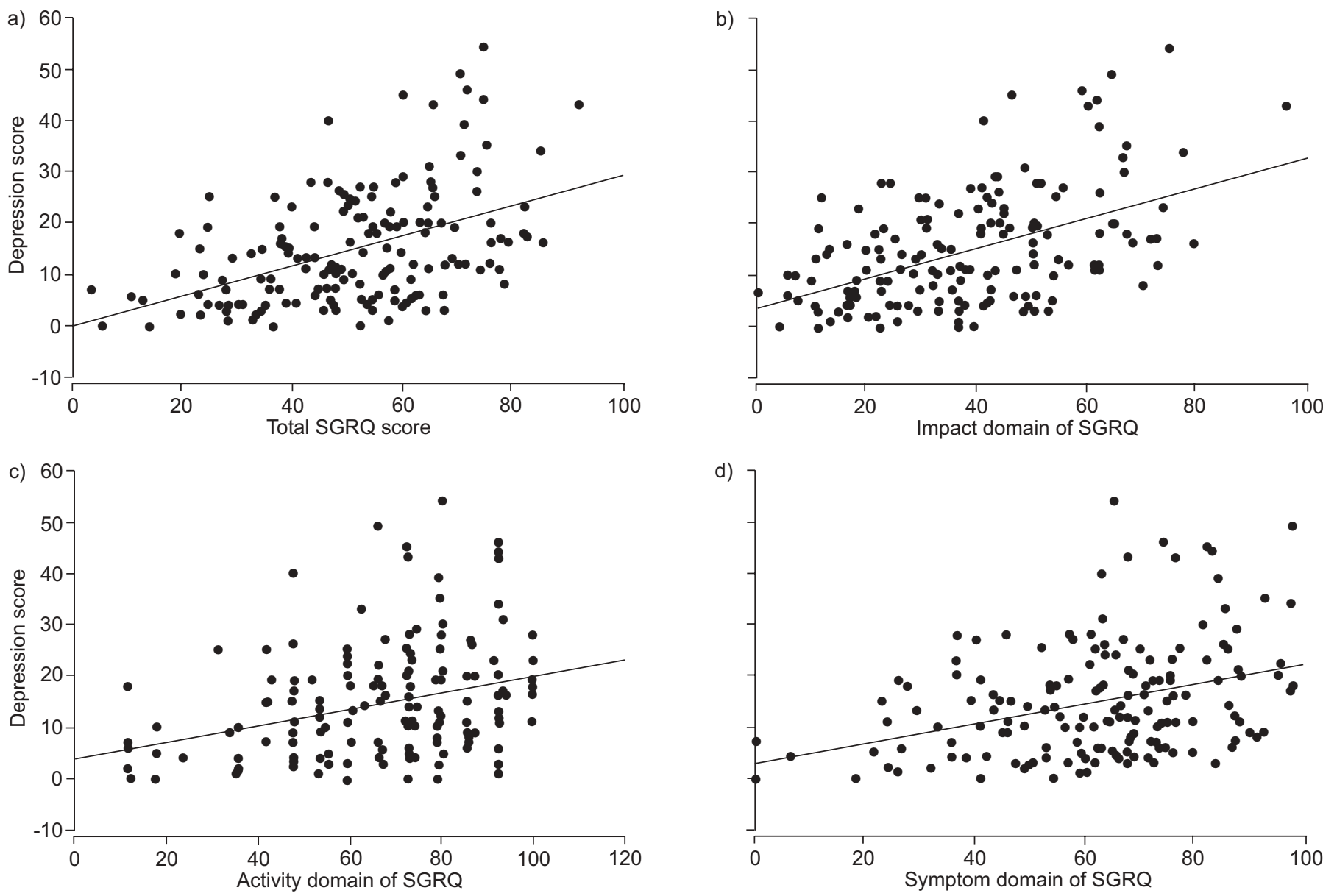

FIGURE 2. Relationship between St George's Respiratory Questionnaire (SGRQ) and depression. a) Worse quality of life (higher total $S G R Q$ score) is related to depression $(r=0.47, p<0.001)$. Impact, activity and symptom were significantly related to depression $(r=0.49, p<0.001 ; r=0.32, p<0.001 ; a n d r=0.35$, $p<0.001)$.

\section{DISCUSSION}

The present study is the first to show a relationship between depression and exacerbation frequency in patients with COPD. The finding that frequent exacerbators are more depressed than infrequent exacerbators is crucial, as exacerbation frequency is an important outcome measure in COPD. Patients prone to frequent exacerbations have faster decline in lung function [10,7], reduced physical activity [4], impaired health status [5] and faster disease progression. Frequent exacerbators also have increased mortality [23], more frequent hospitalisations and therefore increased healthcare costs.

Depression affects how individuals utilise healthcare, and comply with and respond to treatment. Therefore, identifying and treating depression may help to maximise patient outcome and quality of life [15]. Early presentation to healthcare professionals can affect the outcome of an exacerbation and reduce hospitalisation [24]. Depressed patients may be less likely to present early for treatment or to report their exacerbations at all.

Although most COPD exacerbations are treated in the community, they are an important cause of hospitalisation and are responsible for $\sim 10 \%$ of all acute medical admissions [25]. Depression is a strong independent predictor of mortality in COPD patients admitted to hospital for an acute exacerbation [26] and may be a risk factor for frequent admissions [27, 28], as well as being a frequent exacerbator [29]. It was not possible to study the effect of depression on hospitalisation in the present cohort as very few patients were hospitalised during the study.

The present study found that depression is related to a worse quality of life, a higher MRC score, less time spent outdoors, female sex [12] and social isolation [11]. An increased MRC dyspnoea score, which relates to perceived symptoms of dyspnoea, was strongly related to depressive symptoms and less time spent outdoors. Previous studies have shown that awareness of dyspnoea is higher in those who have symptoms of anxiety and depression [30,31]. Higher depression scores may lead more patients to feel breathless or to perceive changes in their symptoms more readily. As depression was closely related to MRC breathlessness score, it is likely that patients underestimate their abilities and do not go out when they are depressed. Current lack of recognition and treatment of depression may have implications for uptake and completion of pulmonary rehabilitation, self-management plans or use of community services. Patients who have an MRC score of 5 have less significant improvement in pulmonary rehabilitation and a higher dropout rate $[32,33]$, which may be due to 


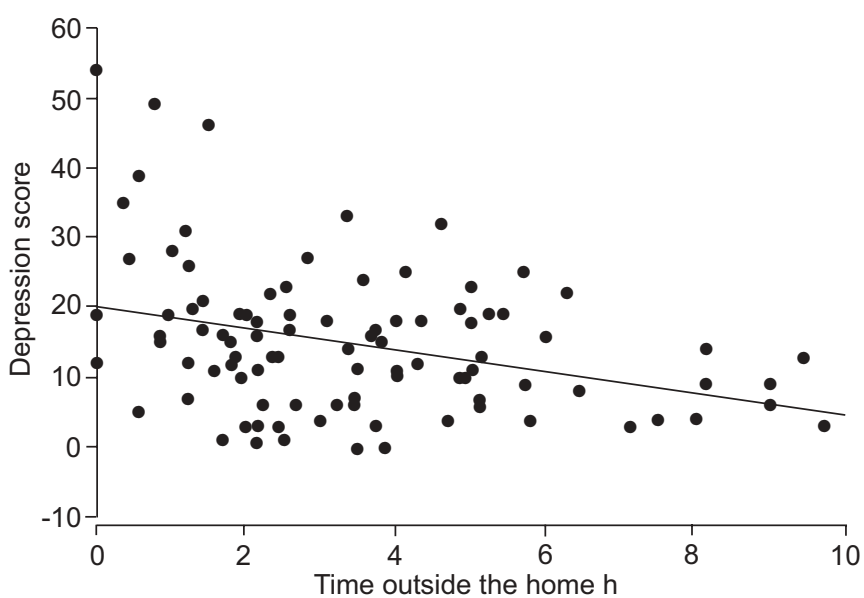

FIGURE 3. Relationship between depression and time spent outdoors $(r=-0.34, p=0.001)$.

unrecognised depression. These data suggest that frequent exacerbators should be routinely screened and treated for depression, if appropriate, and psychological aspects prior to rehabilitation should be addressed. Awareness of social isolation may also partly explain the benefits of pulmonary rehabilitation.

Depression increased acutely at the time of an exacerbation. Factors occurring at exacerbation that raise the CES-D score $>16$ are likely to be of clinical relevance. Therefore, the present authors believe that increased depression at exacerbation is clinically important. Whether the increase in CES-D at the time of exacerbation was due purely to psychological factors or to physical limitations imposed by the exacerbation is difficult to ascertain. Nonetheless, the difference between the frequent and infrequent exacerbators indicates that the psychological impact of an exacerbation is greater on those who are less depressed, i.e. the infrequent exacerbators. Thus, it is essential that this group, in whom psychological intervention at exacerbation may be particularly beneficial, is not overlooked.

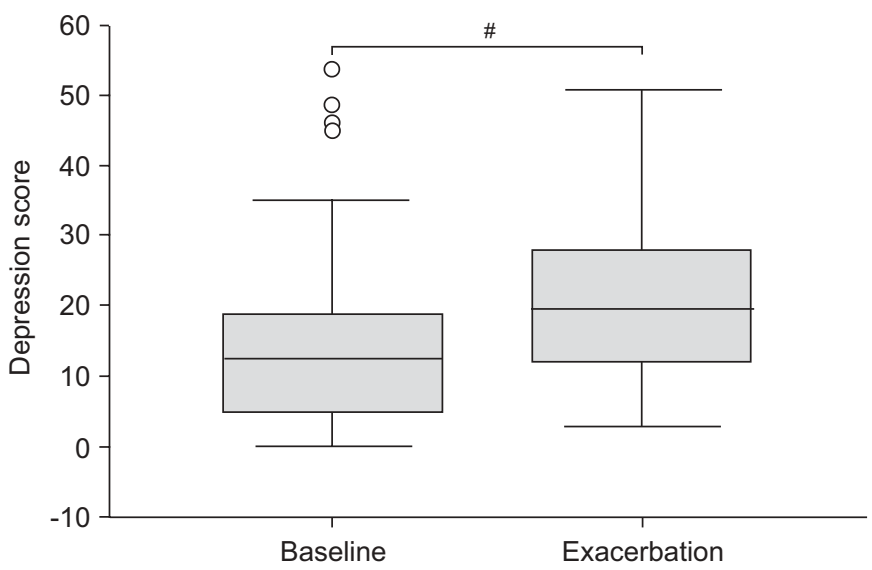

FIGURE 4. Depression score at baseline and exacerbation. Data are presented as median, with the boxes showing the interquartile range and the whiskers representing SD. $O$ : extreme outliers ${ }^{\#}: p=0.03$ (Mann-Whitney).

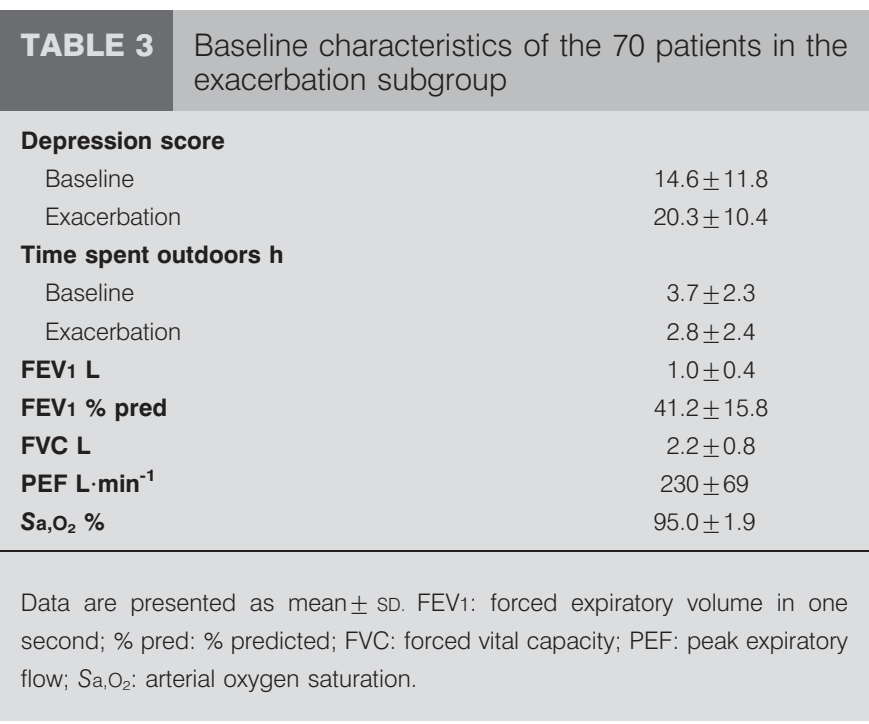

Detailed analysis of groups of specific questions in the CES-D showed that the increased depression seen at exacerbation was mostly due to introversion and reflection. Patients were "bothered by things that do not usually bother them" and "talked less than usual". There is often a negative emotional balance associated with COPD; patients feel guilty that they did not cease smoking, feel that there is a stigma attached with the disease, and often have feelings of frustration, fear and hopelessness [34]. They also have a fear of dying and the increased depression seen at exacerbation may be due to a patient's reflection on death at this time.

There was no relationship between markers of systemic inflammation and depression in COPD patients. Depression has been shown to be linked with systemic inflammation in diseases such as cancer [35], suggesting that the mechanism driving depression in COPD does not have an inflammatory basis. This is consistent with the observation that depression was not linked to severity of disease as defined by Global Initiative for Chronic Obstructive Lung Disease (GOLD) staging. Systemic inflammation has been shown to be linked to GOLD staging [36] and CRP has also been shown to be related to SGRQ [36]. Previous studies have reported depression to be more strongly related to functional status than COPD severity and other studies have shown depression to be more common in severe disease [14].

The present study was conducted in a well-characterised cohort of COPD patients, with robust data for exacerbation frequency. It is possible the present cohort was less depressed than other populations studied as they volunteered to attend frequent outpatient appointments and fill in daily diary cards. However, the prospective nature of the study, accurate calculations of exacerbations frequencies over time from completion of daily diary cards and prompt presentation at exacerbations add to the validity, strength and uniqueness of the depression data. The present study was not designed to look at clinically meaningful changes in depression, but the present authors estimate a change of 1.2 points in the CES-D score would be associated with a 4-point change in the SGRQ. 
The present study has shown for the first time that frequent exacerbators are more depressed than infrequent exacerbators. Depression was more common in females and those with little social contact, and negatively affected the quality of life. The increased depressive symptoms seen at exacerbation reflect patients' increased introversion and contemplation. Understanding the nature of depressive symptoms and treating them is important for improving a patient's quality of life, maximising healthcare utilisation and treatment outcomes.

\section{REFERENCES}

1 Global Initiative for Chronic Obstructive Lung Disease. Global strategy for the diagnosis, management and prevention of chronic obstructive pulmonary disease, 2006. www.goldcopd.com Date last accessed and updated: September 15, 2007.

2 Pitta F, Troosters T, Probst VS, Spruit MA, Decramer M, Gosselink R. Physical activity and hospitalization for exacerbation of COPD. Chest 2006; 129: 536-544.

3 Spruit MA, Gosselink R, Troosters T, et al. Muscle force during an acute exacerbation in hospitalised patients with COPD and its relationship with CXCL8 and IGF-I. Thorax 2003; 58: 752-756.

4 Donaldson GC, Wilkinson TM, Hurst JR, Perera WR, Wedzicha JA. Exacerbations and time spent outdoors in chronic obstructive pulmonary disease. Am J Respir Crit Care Med 2005; 171: 446-452.

5 Seemungal TA, Donaldson GC, Paul EA, Bestall JC, Jeffries DJ, Wedzicha JA. Effect of exacerbation on quality of life in patients with chronic obstructive pulmonary disease. Am J Respir Crit Care Med 1998; 157: 1418-1422.

6 Spencer S, Jones PW, GLOBE Study Group. Time course of recovery of health status following an infective exacerbation of chronic bronchitis. Thorax 2003; 58: 589-593.

7 Donaldson GC, Seemungal TA, Bhowmik A, Wedzicha JA. Relationship between exacerbation frequency and lung function decline in chronic obstructive pulmonary disease. Thorax 2002; 57: 847-852.

8 O'Brien JA, Ward AJ, Jones MK, McMillan C, Lordan N. Utilization of health care services by patients with chronic obstructive pulmonary disease. Respir Med 2003; 97: Suppl. A, S53-S58.

9 Groenewegen KH. Schols AM, Wouters EF. Mortality and mortality-related factors after hospitalization for acute exacerbation of COPD. Chest 2003; 124: 459-467.

10 Kanner RE, Anthonisen NR, Connett JE, Lung Health Study Research Group. Lower respiratory illnesses promote FEV1 decline in current smokers but not ex-smokers with mild chronic obstructive pulmonary disease: results from the lung health study. Am J Respir Crit Care Med 2001; 164: 358-364.

11 van Manen JG, Bindels PJ, Dekker FW, Ijzermans CJ, van der Zee JS, Schadé E. Risk of depression in patients with chronic obstructive pulmonary disease and its determinants. Thorax 2002; 57: 412-416.

12 Di Marco F, Verga M, Reggente M, et al. Anxiety and depression in COPD patients: The roles of gender and disease severity. Respir Med 2006; 100: 1767-1774.
13 Kunik ME, Roundy K, Veazey C, et al. Surprisingly high prevalence of anxiety and depression in chronic breathing disorders. Chest 2005; 127: 1205-1211.

14 van Ede L, Yzermans CJ, Brouwer HJ. Prevalence of depression in patients with chronic obstructive pulmonary disease: a systematic review. Thorax 1999; 54: 688-692.

15 Eiser N, Harte R, Spiros K, Phillips C, Isaac MT. Effect of treating depression on quality-of-life and exercise tolerance in severe COPD. COPD 2005; 2: 233-241.

16 Seemungal TAR, Donaldson GC, Bhowmik A, Jefferies DJ, Wedzicha JA. Time course and recovery of exacerbations in patients with chronic destructive pulmonary disease. Am J Respir Crit Care Med 2000; 161: 1608-1613.

17 Bestall JC, Paul EA, Garrod R, Garnham R, Jones PW, Wedzicha JA. Usefulness of the Medical Research Council (MRC) dyspnoea scale as a measure of disability in patients with chronic obstructive pulmonary disease. Thorax 1999; 54: 581-586.

18 Jones PW, Quirk FH, Baveystock CM, Littlejohns P. A selfcomplete measure of health status for chronic airflow limitation. The St. George's Respiratory Questionnaire. Am Rev Respir Dis 1992; 145: 1321-1327.

19 Radloff LS. The CES-D scale: a self-report depression scale for research in the general population. Appl Psychol Measurement 1977; 1: 385-401.

20 Burnam MA, Wells KB, Leake B, Landsverk J. Development of a brief screening instrument for detecting depressive disorders. Med Care 1988; 26: 775-789.

21 Hurst JR, Donaldson GC, Wilkinson TM, Perera WR, Wedzicha JA. Epidemiological relationships between the common cold and exacerbation frequency in COPD. Eur Respir J 2005; 26: 846-852.

22 Bhowmik A, Seemungal TA, Sapsford RJ, Wedzicha JA. Relation of sputum inflammatory markers to symptoms and lung function changes in COPD exacerbations. Thorax 2000; 55: 114-120.

23 Soler-Cataluña JJ, Martínez-García MA, Román Sánchez P, Salcedo E, Navarro M, Ochando R. Severe acute exacerbations and mortality in patients with chronic obstructive pulmonary disease. Thorax 2005; 60: 925-931.

24 Wilkinson TM, Donaldson GC, Hurst JR, Seemungal TA, Wedzicha JA. Early therapy improves outcomes of exacerbations of chronic obstructive pulmonary disease. Am J Respir Crit Care Med 2004; 169: 1298-1303.

25 Hospital Episode Statistics, UK Department of Health 2003. www.dh.gov.uk/PublicationsAndStatistics/Statistics/ HospitalEpisodeStatistcs/fs/en Date last accessed: April 20, 2007.

26 Almagro P, Calbo E, Ochoa de Echagüen A, et al. Mortality after hospitalization for COPD. Chest 2002; 121: 1441-1448.

27 Dahlén I, Janson C. Anxiety and depression are related to the outcome of emergency treatment in patients with obstructive pulmonary disease. Chest 2002; 122: 1633-1637.

28 Yohannes AM, Baldwin RC, Connolly MJ. Depression and anxiety in elderly outpatients with chronic obstructive pulmonary disease: prevalence, and validation of the BASDEC screening questionnaire. Int J Geriatr Psychiatry 2000; 15: 1090-1096.

29 Garcia-Aymerich J, Farrero E, Félez MA, et al. Risk factors of readmission to hospital for a COPD exacerbation: a prospective study. Thorax 2003; 58: 100-105. 
30 Neuman A, Gunnbjörnsdottir M, Tunsäter A, et al. Dyspnea in relation to symptoms of anxiety and depression: A prospective population study. Respir Med 2006; 100: 1843-1849.

31 Ferguson CJ, Stanley M, Souchek J, Kunik ME. The utility of somatic symptoms as indicators of depression and anxiety in military veterans with chronic obstructive pulmonary disease. Depress Anxiety 2006; 23: 42-49.

32 Garrod R, Marshall J, Barley E, Jones PW. Predictors of success and failure in pulmonary rehabilitation. Eur Respir J 2006; 27: 788-794.

33 Wedzicha JA, Bestall JC, Garrod R, Garnham R, Paul EA, Jones PW. Randomized controlled trial of pulmonary rehabilitation in severe chronic obstructive pulmonary disease patients, stratified with the MRC dyspnoea scale. Eur Respir J 1998; 12: 363-369.

34 Kessler R, Ståhl E, Vogelmeier C, et al. Patient understanding, detection, and experience of COPD exacerbations: an observational, interview-based study. Chest 2006; 130: 133-142.

35 Jehn CF, Kuehnhardt D, Bartholomae A, et al. Biomarkers of depression in cancer patients. Cancer 2006; 107: 2723-2729.

36 Broekhuizen R, Wouters EF, Creutzberg EC, Schols AM. Raised CRP levels mark metabolic and functional impairment in advanced COPD. Thorax 2006; 61: 17-22. 